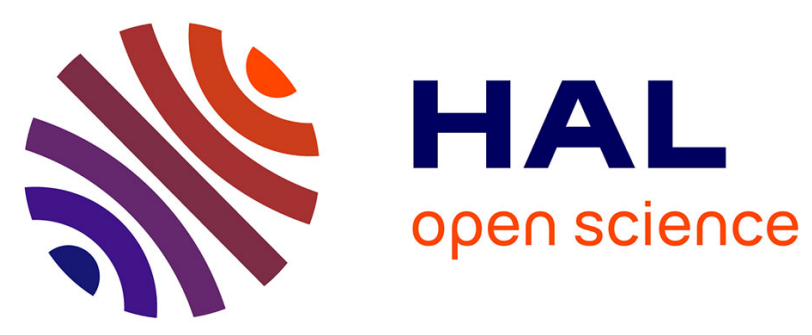

\title{
From urban concept to urban engineering: The contribution of distributed collaborative design to the management of urban projects
}

Laurent Dupont, Vida Gholipour, Laure Morel, Jean-Claude Bignon, Claudine Guidat

\section{To cite this version:}

Laurent Dupont, Vida Gholipour, Laure Morel, Jean-Claude Bignon, Claudine Guidat. From urban concept to urban engineering: The contribution of distributed collaborative design to the management of urban projects. Journal of Urban Design, 2012, 17 (2), pp.255-277. 10.1080/13574809.2012.666208 . hal-00734951

\section{HAL Id: hal-00734951 \\ https://hal.science/hal-00734951}

Submitted on 26 Sep 2016

HAL is a multi-disciplinary open access archive for the deposit and dissemination of scientific research documents, whether they are published or not. The documents may come from teaching and research institutions in France or abroad, or from public or private research centers.
L'archive ouverte pluridisciplinaire HAL, est destinée au dépôt et à la diffusion de documents scientifiques de niveau recherche, publiés ou non, émanant des établissements d'enseignement et de recherche français ou étrangers, des laboratoires publics ou privés. 


\title{
From urban concept to urban engineering: The contribution of distributed collaborative design to the management of urban projects
}

\author{
Laurent DUPONT ${ }^{1, \mathrm{a}}$, Vida GHOLIPOUR ${ }^{2, \mathrm{a}, \mathrm{b}}$, Laure MOREL ${ }^{3, \mathrm{a}}$, Jean-Claude BIGNON ${ }^{4, \mathrm{~b}}$, \\ Claudine GUIDAT ${ }^{5, \mathrm{a}}$. \\ ${ }^{1}$ Doctor, e-mail: 1.dupont@univ-lorraine.fr \\ ${ }^{2}$ Ph.D. student, e-mail: vida.gholipour@gmail.com \\ ${ }^{3}$ Professor, e-mail: laure.morel@univ-lorraine.fr \\ ${ }^{4}$ Professor, e-mail: jean-claude.bignon@crai.archi.fr \\ ${ }^{5}$ Professor, e-mail: claudine.guidat@univ-lorraine.fr \\ ${ }^{a}$ ERPI, Université de Lorraine \\ Equipe de Recherche sur les Processus Innovatifs - (Innovative Process Research Team) \\ 8 rue Bastien Lepage - BP 90647 - 54010 NANCY Cedex - France \\ ${ }^{\mathrm{b}}$ MAP-CRAI, Ecole Nationale Supérieure d'Architecture de Nancy \\ 2 rue Bastien-Lepage - B.P. 40435 - 54001 Nancy Cedex \\ Tel: +33 383308134 ; Fax: +33383308127
}

\begin{abstract}
:
The complexity of urban systems is an increasingly common topic in academic literature. Following in the footsteps of the industrial sector, which has understood this issue for many years now, urban engineering must also tackle the challenges created by complex systems. Industrial engineering has provided a number of responses to this challenge, including design technologies, which are notably collaborative. It seems possible, at least in theory, to transfer a number of best practice methods and adapt these to the conceptualisation of urban development projects (in the initial phase) in order to encourage their global management (in terms of strategic decision-making) and their social acceptability. The challenge is then to formulate new methodological models, as well as to create an environment dedicated to their application.
\end{abstract}

Keywords: Complexity of urban systems; urban engineering; technology transfer; distributed collaborative design. 


\section{Introduction}

This article brings together a raft of new issues which the urban sector must tackle in order to better respond to customer needs. Thus, we give new developments to the researches in the urban field which focus on the initial phase. As a result, we hope to contribute to a new definition of the management of urban development through the integration of the collective design environment into the resolution of urban issues. We will start by explaining why it is impossible to ignore the complexity of urban systems and emphasising that urban engineering must take this complexity into account. We will then observe that industry has developed technological solutions to manage its "own" complexity, in particular in the field of design (for processes and products). A review of the literature in this sector will help to describe, compare and understand both distributed and collaborative main patterns of design.

We will then discuss potential transfers from the field of design to urban issues. The contribution of design is especially relevant in the initial stage where it is easier to influence economical, social and environmental benefits than in other stages. Of course, we will also highlight potential difficulties or adaptations which may be required. As a result of our line of reasoning, we will investigate the Distributed Collaborative Design (DCD) concept as the best practice to be adapted and we will formulate the tools, methods and environment necessary for the development of DCD dedicated to urban issues. Finally, in conclusion, we will discuss the likely consequences of our contribution to the conceptualisation of urban engineering on urban systems. We will particularly emphasise the social dimension due to the predominance of stakeholders.

In addition, we can indicate that the French National Centre for the Management of Territorial Services (CNFPT) asked the Development and Urban Planning Agency of the Urban Area of Nancy (ADUAN) to develop new methodologies in order to understand and manage better the urban systems. The basic idea was to develop and experiment new urban projects design in the built-up area of Nancy and then to evaluate the potential use at the national scale. This article highlights the theoretical and methodological part of our work.

\section{Complexity of urban systems 1.1. Some elements of theory}

A bibliometric analysis in the work of Dupont (2009, pp.27-30), studying the links between "complexity" and "urban environment" shows, among the main contributing scientific disciplines identified (Environmental Science, Engineering, Earth and Planetary Sciences, Social Science, Medicine), there is a new expansion of publications in the engineering sector at the end of the first decade of 2000. It seems the association of these issues interests researchers. This result might indicate that the scientific community is attempting to fill in a lack of specific tools and methodologies ${ }^{1}$.

Furthermore, the state of art shows a number and range of recent publications which apply the same concepts in different contexts; it is interesting to return to the original definition to build a robust theoretical approach to urban complex systems.

Complex systems have been studied for years, and it thus seems necessary to return to a number of main concepts and to remind ourselves of certain defining elements. Firstly, we can observe that studying the concept of "city" involves a number of interconnected factors which all need to be taken into account. This can be illustrated using the example given by Salet (2008), who explains that "all over urban Europe, the traditional shape of mono-centric urban systems is being transformed into a

\footnotetext{
${ }^{1}$ A search realized in Scopus returned a total of 604 articles published between 1980 and 2009 included in various disciplines. The year 2010, during which our analysis was performed, was excluded because it is not relevant. We were therefore careful to exclude specific keywords connected to the word "complex" such as "AIDS-Related Complex" or "Vitamin B complex" or "Complex mixtures", etc. This selection filter resulted in a final list of only 430 articles.
} 
complex mosaic of poly-centric urban configurations".

All of these elements operate on different temporal and spatial scales. We must therefore understand the city as a set of elements which are related to each other and which constitute " $a$ whole at the same time organised, organising, and organiser" (Morin, 2005a, p.11).This is also the definition of a system. A city is an urban system which cannot be determined or explained by its component parts alone.

Urban systems cannot be analysed in the same way as hyper-complicated systems, for several reasons: the impossibility exhaustively enumerating the widely diversified connections between the multiple parts of this kind of system, the indescribable nature of the rules or programmes which run the system, and the unpredictability of the possible behaviours of its different components (Le Moigne, 1993). In addition, social phenomena specific to cities create non-linear systems from the moment that personal interaction generates catalyst effects. Every single moment produces fluctuations which society can then weaken or amplify (Prigogine, 1996). Human systems are thus living organisations, in which the "laws of living organisation are not stable but unstable, remedied for and compensated for, and yet stabilised in terms of their dynamics" (Morin, 2005b, p.31).

When studying cities, we face richly organised systems which incorporate numerous interactions and interferences between a large number of units. These organisations are also constituted by uncertainties, areas of shadow and phenomena of emergence, which designate characteristics and qualities that appear once the organisation of a system is constituted (Monod, 1970). These phenomena are certainly understandable, but occur randomly. This potential unpredictability in the behaviour of urban systems is particularly due to the "recursive loop". This means that urban systems are a self-generating and self-reproducing process. They are affected by positive or negative feedback ${ }^{2}$. Thus, according to the different elements of the definition of "complexity", which has been the subject of in-depth development by researchers, the above-mentioned dimensions all come together to comprise the complexity of urban systems.

It is possible to draft the following generic report using only the specialist literature, regardless of the country and size of the city: cities are complex urban systems which must be approached using the appropriate paradigm. This complexity is a predominant element in our analysis of the development of projects which result from urban issues.

Urban engineering aims to develop tools, methodologies and environment to better consider urban issues. In fact, the main objective is to ensure their effectiveness within complex systems.

According to Morin (2005a), we accept that (urban) systems comprise more than the simple addition of the qualities and properties of their component parts and yet at the same time also less than the sum of their parts. Actually, the organisation of these component parts into a whole reveals new qualities or properties, while others disappear. Both of these characteristics are central to an understanding of urban systems. Thus, they are self-products and self-producers. An analysis of an urban system and its urban issues can focus on the separate study of parts of the system, as well as on their interconnections. The bibliometric approach mentioned above shows that a number of disciplines appears interested in parts of the urban system and contribute to an enhanced understanding of certain elements. The complexity of urban systems leads us to the logical conclusion that neither the components nor the couplings are separate, and a global approach is in this situation very relevant.

The experience gained from industrial issues appears relevant at this point. Industrial engineering uses the design sector to develop specific technological solutions to tackle its own complex issues. A possible point of interest might be to study the possibility of transferring certain technologies designed by the industrial sector.

\subsection{Adapting industrial sector experience of complexity to urban issues}

\footnotetext{
${ }^{2}$ Example cited by Morin (2005a); for further explanation: Rosenblueth, A., Wiener, N. and Bigelow, J., 1943. Behavior, Purpose and Teleology In: Philosophy of Science, 10, S. 18-24. Http://pespmc1.vub.ac.be/Books/Wiener-teleology.pdf, accessed 28 May 2009.
} 
It has been common knowledge for years in the industry sector that design is not only a collective activity (De Terssac, 1996), but also a cognitive process, because knowledge is involved. More accurately, the design process is an ongoing process which requires the support of all the stakeholders involved in the product or service designed (Darses et al., 2001). During a design process, a design object (which can be a process or a product) cannot be considered as a single isolated object. It must be comprehended from various points of view. As such, the design team must cope with problems containing a high number of variables. One consequence of this complexity is that the resolution of industrial problems often requires that multiple competences be brought together, which leads to the development of collaboration within single work groups (Darses et al., 2001). This can be illustrated by the decision-making process within the design process, as stated by Belkadi, Bonjour and Dulmet (2004) in which the design activity is a decisional activity, in which several decision-makers cooperate in order to take into account the impact of an upstream decision on a downstream decision and vice-versa. The component parts of a design issue are connected even if they depend on different specialists. As a consequence, however, conceptual divergences between different practice communities can occur. This is one of four barriers, underlined by Fischer (2004), which can impede the design process. The author also mentions spatial (across distance), temporal (across time) and technological barriers (between persons and objects). Practice shows that it is necessary to transcend boundaries, to extend beyond the boundaries between knowledge, skills, know-how and sectors, etc. In the design sector, this "decompartimentalisation" or "opening up" involves collective effort. In general terms, consistent with Belkadi, Bonjour and Dulmet (2004), design is a complex field that requires a global approach as well as collective effort from the internal or external partners in the design process.

Efforts must be coordinated in order to be constructive - this involves developing collective processes with specific methods, tools and environments.

Finally, we can illustrate the general process to explain the complexity involved using the following diagram (Figure 1):

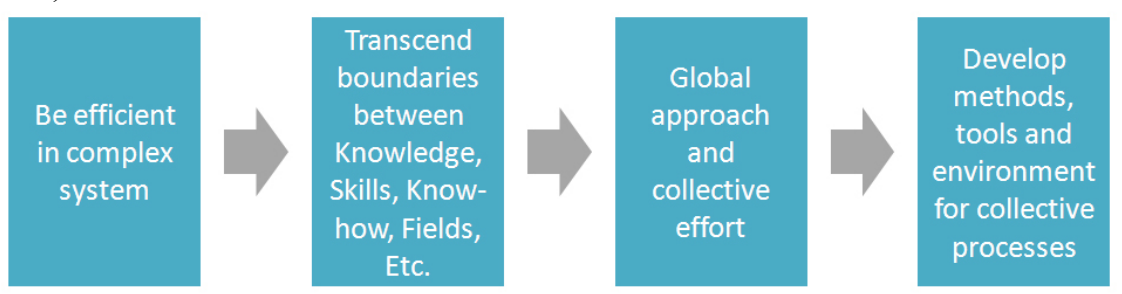

Figure 1: Model of the industrial issues experience with complexity

\section{Scientific background to collective design methods}

In this section of this paper, we will review the main types of collective design process which have been put forward in team projects. Firstly, there is distributed design, in which design team members are assigned clearly separated tasks and duties towards a mutual objective. This was a primary response to the question of complexity. Secondly, there is collaborative design, in which the roles of design team members overlap widely. This is a second response to complex systems.

Globalization has had consequences for workers and work places in terms of impact of new information technologies, changing work structures and changing industrial relations systems (Wilpert, 2009). In order to adapt engineering design strategies to new market and working contexts, many academic discussions focus on the collaborative design method as a solution (Figure 2). In an industrial context, the collaborative design method is currently an important part of networked manufacturing, as it provides improvements through knowledge management (Hou, Su and Wang, 2008a). 
Draft - Dupont et al 2012 From urban concept to urban engineering: ...

See published version : http://dx.doi.org/10.1080/13574809.2012.666208

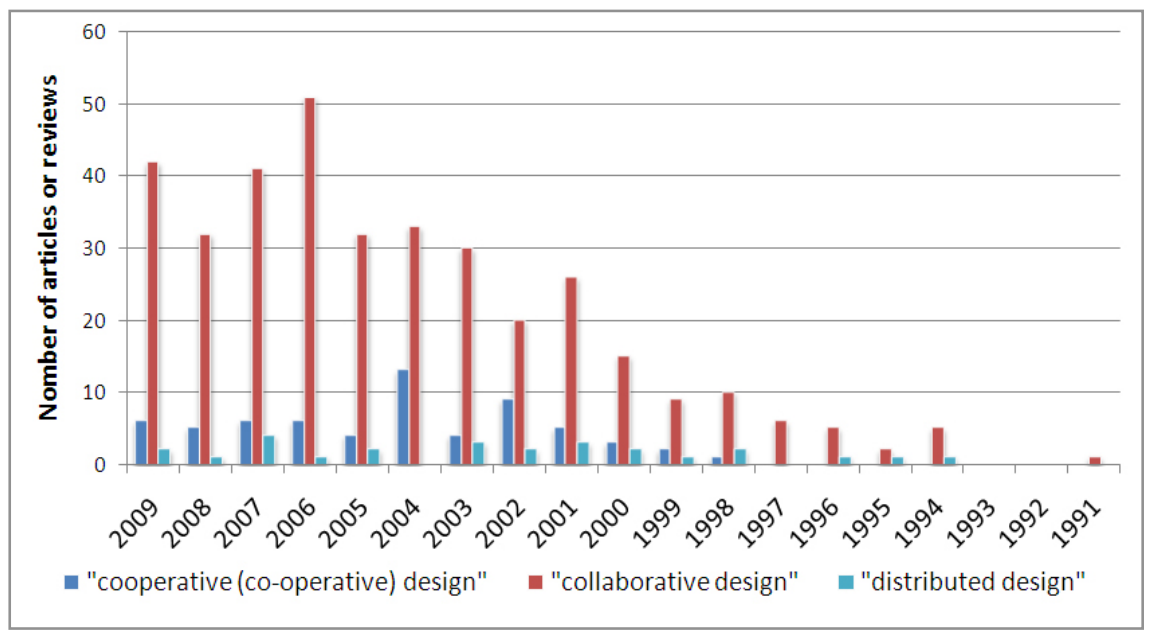

Figure 2: Contribution of scientific articles or reviews whose title contains the words "distributed design" or "collaborative design" or "cooperative design", per year from 1991 to end-2009

'In fact, the purpose of most recent studies and proposals based on the different forms of design process can be seen as searches for more suitable solutions to the current industrial challenges posed by the complexity of society. We aim to study the possibility of adapting technologies. Our objective is therefore to obtain an understanding of these different technological elements through methodical and exhaustive consideration. The purpose here is to define the development of best practice in design. According to a review of the literature, the cooperative design concept is sometimes used instead of collaboration (Wang, Shen and Xie, 2002) or is considered as sub-section of collaboration (Shen, Norie and Barthes, 2000; Kvan, 2000). Some further researches explain cooperation as a solution or a support to effective and successful collaborative design (Slimani, Ghodous and Boujut, 2005). So we believe that contrary to distributed and collaborative design, cooperative design has no strategic characteristics. In the followings sections, we will take a look at distributed design and collaborative design.

\subsection{Distributed Design}

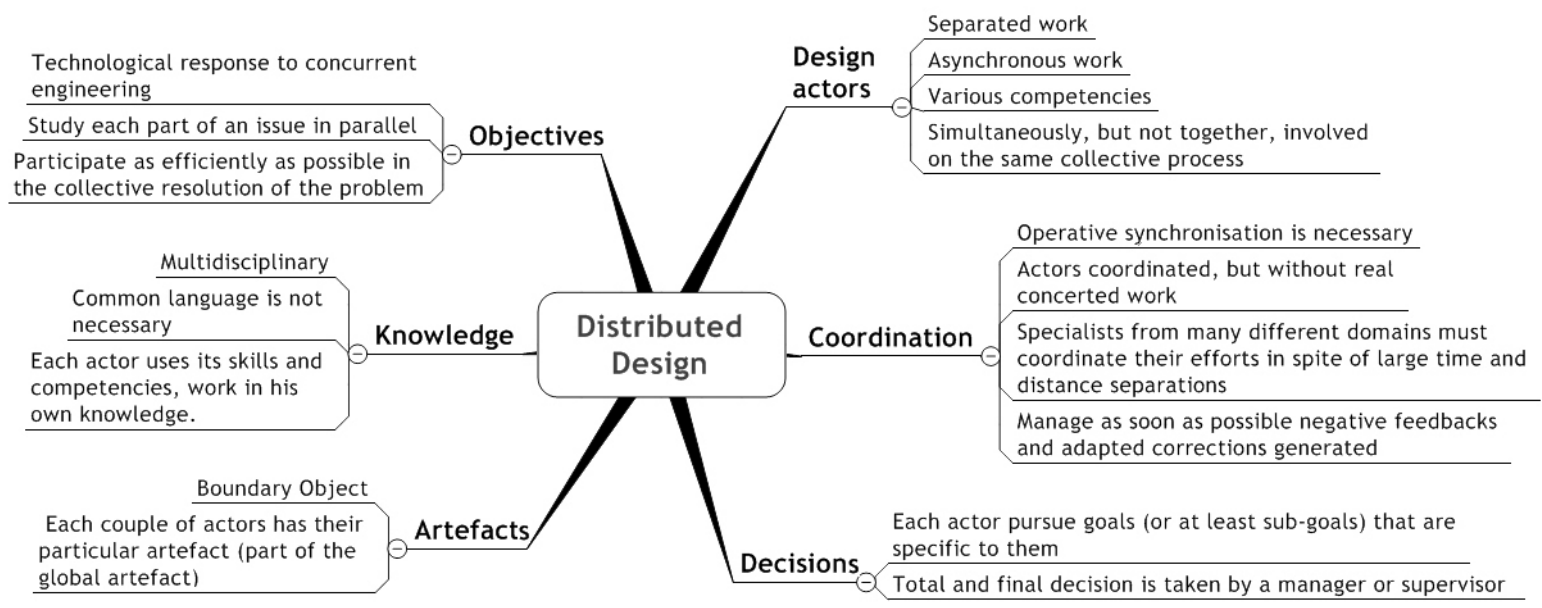

Figure 3: Mind map of distributed design characteristics

A heuristic diagram (Figure 3) shows a mind map $^{3}$ of distributed design characteristics provided by a

\footnotetext{
${ }^{3}$ According to Buzan (2000), the Mind-Map notably helps to pull out the strong ideas and the hierarchies from linear information. That's an efficient tool both to collect and represent the information of the third parts to evaluate the quality of their reflection.
} 
literature review about (Distributed) Design. Six dimensions can be observed: Objectives, Design actors, Knowledge, Coordination, Artefacts ${ }^{4}$, and Decisions.

Objectives: The method of distributed design is a technological response to concurrent engineering both on produced aspects and process. Studying every part of an issue in parallel is another aim of this design method. Each expert can perform a pre-determined task, as required in the project plan. This thus gives the experts a range of independence (Visser, Darses and Détienne, 2004). Even if the actors do not work directly together, they are engaged so as to participate as efficiently as possible in the collective resolution of the problem (Darses, Detienne and Falzon, 2001).

Design actors: Essentially, design actors in a distributed design context engage in separated work in parallel. Design actors do not share their knowledge with other actors. It is thus possible to conclude that this design method comprises an asynchronous working method. Actors have various competencies and they are simultaneously, but separately, involved in the same collective process.

Knowledge: Multidisciplinary knowledge is a particularity of this design method. It is not necessary to develop a common language because each actor uses their skills and competencies, and works using his or her own knowledge. Each actor is therefore free with his vocabulary except in some situations where an expert requires the advice of another.

Coordination: As a multidisciplinary work method and with regard to barriers (time and distance) between actors, coordination is a key success factor in this design method. Operational synchronisation is necessary in order to manage the design process and to coordinate the different actors. Specialists from a wide variety of different domains must coordinate their efforts, sometimes in spite of large time and distance separations (Fischer, 2004).

Artefacts: In the distributed design method, artefacts can be viewed as "boundary objects" because they concentrate knowledge and potential explanations as actors communicate through the artefact (Fischer, 2004; Grebici, 2007). In this case, each pair of actors shares their own particular artefact, which then forms part of a global artefact.

Decisions: Each actor pursues goals (or at least sub-goals) that are specific to them (Darses, Detienne and Falzon, 2001); these sub-goals require them to envisage sub-decisions, for which responsibility is individual. The full and final decision (the validation of the concept or final artefact) will be taken by a manager or supervisor.

\footnotetext{
${ }^{4}$ The artefact is the industrial process or product which is created through the design process. It fuels the stage of development (output).
} 


\subsection{Collaborative design}

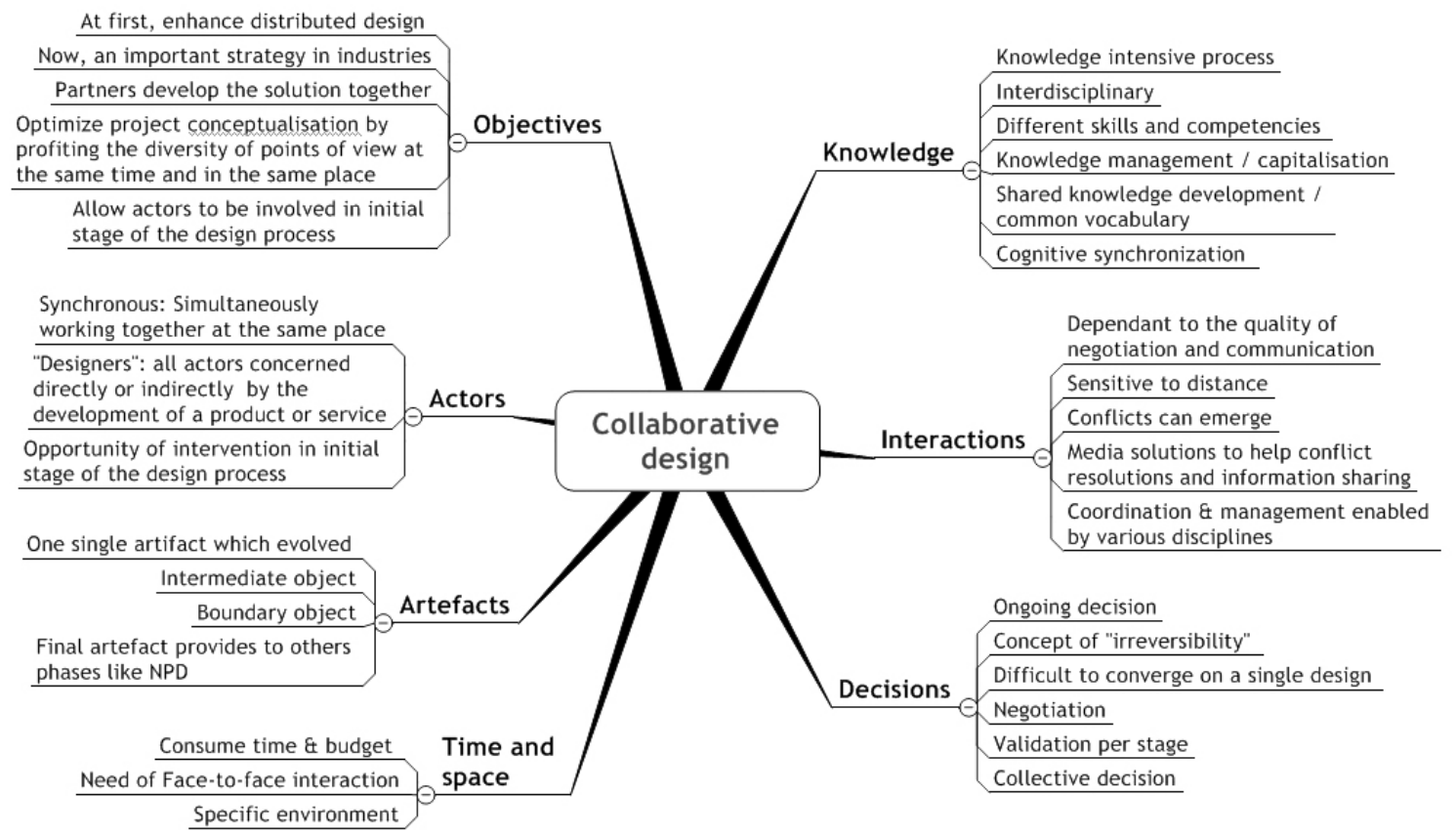

Figure 4: Mind map of collaborative design characteristics (in a B2B context)

After consulting various studies on and description of the collaborative design process, it is possible to summarise its main characteristics in seven sub-studies: Objectives, Decisions, Actors, Interactions, Artefacts, Knowledge and finally Time and Location (Figure 4). We will explain what is meant by each of these sub-studies by referring to the literature. This description is related to a collaborative design in a Business to Business (B2B) context, and presumes that all design actors are professionals.

Objectives: Kvan (2000, p.410) states that "collaboration can be thought of as joint problem solving. It means working with others with shared goals for which the team attempts to find solutions that are satisfactory to all concerned." One of the most important objectives of this design strategy is to add to certainty in design, and thus reduce subsequent unnecessary reworking. Collaborative design allows actors to be involved in the initial stage of the design process and thus prevent posteriori tests (Grégori and Brassac, 2001). Finally, collaborative design is often applied to new product development (NPD) to enhance the product development ability of a business (Hou, Su and Wang, 2008a).

Actors: Collaborative engineering design is a human-based, interdisciplinary and sociotechnical activity $(\mathrm{Lu}, 2000)$. The product or process is result of a "joint effort by many designers" (Wang, Shen and Xie, 2002) who should be representative of various competences because problems often require that multiple competences be brought together (Darses, Détienne and Falzon, 2001). During the collaborative design process, actors should be in physical proximity (i.e. in the same place) (Darses and Falzon, 1996; Grégori and Brassac 2001) or in virtual proximity (Wang, Shen and Xie, 2002; Khadidjia, 2007) and work at the same time. In summary, the resulting quality of the design is likely to be affected by both the physical and psychological presence of the stakeholders and their ability to keep an open mind even as they stand up for their ideas.

Interactions: Here, an artefact is the result of a series of interactions between the members

\footnotetext{
${ }^{5}$ Here, the term "designer" refers not only to design professionals but also to all other actors who are directly or indirectly impacted by the design process.
} 
of the design team who negotiate for a shared understanding. The relationships between the design actors depend on the collaborative work context and impact the quality of the result (Robin, Rose and Girard, 2007). Gabriel and Maher (2002, p.199) explain that the communication of ideas between actors is "in the form of verbal representations (voiced or typed) and graphical representations" when actors are engaged in face-to-face collaboration. If the actors were geographically displaced, the interaction is space-affected, and may possibly also be time-affected (Gabriel and Maher, 2002). Many of the conflicts in this strategy are related to interactions because "roles often overlap" (Belkadi, Bonjour and Dulmet, 2004). Conflict resolution is still mostly sought through negotiations and face-toface meetings (Wang, Shen and Xie, 2002). Furthermore, the partner selection has importance to reduce the risks of conflict (Hou et al., 2008b). Finally, various disciplines can help to manage and coordinate interactions: cognitive psychology, ergonomics, computing and industrial engineering (Belkadi, Bonjour and Dulmet, 2004).

Knowledge: Collaborative design is located at the crossroads of various disciplines (Belkadi, Bonjour and Dulmet, 2004) and could be considered as an "interdisciplinary and socio-technical activity" (Lu et al., 2000, p.70). In "interdisciplinary design" of this kind (Wang, 2002, p.988), knowledge is also interdisciplinary and can be characterised as "mindbody-thing practice" (Amin and Cohendet, 2004, p.83). In an industrial setting, collaborative product design is a knowledge-intensive process that ranges from conceptual design (in the early stages of design) to performance evaluation (Chen, 2008). Knowledge management can be improved by collaborative design (Hou et al., 2008c).

Decisions: Collaborative decision-making is an "irreversible process" (Brassac and Grégori, 2003, p.87). This means that while actors work together, they generate a succession of decisions, consciously or otherwise, through the interaction of their knowledge. The final decision is taken in series of multiple critical discussions and supporting proposals between stakeholders. Accordingly there are undeniably strong interdependencies between design decisions.

Artefacts: Here, the artefact is the centre of collective work and "there is an interaction between any actor and the object of design (the design artefact)" (Robin, Rose, and Girard 2007, p.187). Consequently, "design artefacts are not designed once and for all, but instead evolve over long periods of time" (Fischer, 2004, p.154). Artefacts can also be viewed as "boundary objects" because they help stakeholders to incrementally increase shared understanding (Fischer, 2004, p.158; Grebici, 2007, p.87). Visser, Darses and Détienne (2004, p.109) talk about "cognitive artefact" which makes easier the work between specialists of different disciplines. These objects through the external representation that they give help to the sharing of a common understanding. To finish, the final artefact (a product or a service) fuels the next stages of the global process as the prototyping or the development (Caelen, 2004a).

Time and space: Despite of the progress of the technologies of the information and their application to the collaborative processes, according to Fischer (2004), the distance is a further barrier, proper to the collaborative design. Interactions are affected spatially and temporally and actors that are not in situation of collaboration in opposite always had the possibility to collaborate by the aid of the telephone, the fax machine as it could have been observed (Gabriel and Maher, 2002). All the more it is easier to collaborate when environment of design is suitable to it (Robin, Rose and Girard, 2007).

\subsection{Synthesis of the considered design methods}

In conclusion, design processes have developed from a distributed mode, where each profession deals with its problems separately, to a systemic mode, where different professionals assess a solution together (Caelen, 2004a). According to Darses and Falzon (1994), this means that it is necessary to 
evolve from an operational synchronisation to a cognitive synchronisation. In the context of industry, the design team can to a certain extent be brought together for the design of several products. The collaboration can be seen as a long-term investment. All the more the collaborative design is a process "typically expensive and time consuming" (Klein et al., 2003, p.201) if this one is not optimized. An organization will then pitch on a distributed or collaborative strategy, according to its needs and resources.

Table 1 gives an overview of the main elements of the two main design strategies which have been discussed in this paper.

Table 1: Synthesis of the main elements described in the literature

\begin{tabular}{|c|c|c|}
\hline Design method & Distributed & Collaborative \\
\hline $\begin{array}{l}\text { Main necessary } \\
\text { operational } \\
\text { characteristics }\end{array}$ & $\begin{array}{l}\text {-Operative synchronization } \\
\text {-Negotiation following the development of the } \\
\text { artefact } \\
\text {-Correction and validation at the end of the } \\
\text { design process } \\
\text {-Multidisciplinary process } \\
\text {-No need to develop a common language } \\
\text {-Management and coordination by at least one } \\
\text { person }\end{array}$ & $\begin{array}{l}\text {-Cognitive synchronization } \\
\text {-Negotiation during the development of the artefact } \\
\text {-Corrections and validations are an ongoing process } \\
\text {-Interdisciplinary process } \\
\text {-Development of a common knowledge } \\
\text {-Shared sense of common work / Serious need to adhere to shared } \\
\text { rules and tasks } \\
\text {-Time and budget must be planned early in order to organize } \\
\text { collaborative sessions } \\
\text {-Shared time and space } \\
\text {-Methods of representation }\end{array}$ \\
\hline $\begin{array}{l}\text { Important } \\
\text { observation on } \\
\text { the process }\end{array}$ & $\begin{array}{l}\text {-Strong dependence on coordination } \\
\text {-Probable additional cost incurred by final } \\
\text { corrections }\end{array}$ & $\begin{array}{l}\text {-Difficult to obtain a shared decision, but once established, this is } \\
\text { more robust (see the concept of "irreversibility") } \\
\text { - Contextual elements (technologies, actors, environment, "outer } \\
\text { background") directly affect design process and product. }\end{array}$ \\
\hline $\begin{array}{l}\text { Main potential } \\
\text { waited results }\end{array}$ & $\begin{array}{l}\text {-Knowledge capitalization in the artefact } \\
\text { increases through designers' group efforts. } \\
\text {-Improved product quality in less time } \\
\text { compared to a design lacking strategic } \\
\text { methods. } \\
\text {-It is about a collective process but it's a } \\
\text { "separated collective", i.e. this is not a direct } \\
\text { collaboration. Each one and its environment } \\
\text { evolve separately. }\end{array}$ & $\begin{array}{l}\text {-Knowledge capitalization in the artefact increases, as does the } \\
\text { knowledge of design actors thanks to interdisciplinary exchanges. } \\
\text {-A product with a more global approach: } \\
\text { •Added-value design team. } \\
\text {-An investment for next projects. } \\
\text {-In optimum conditions, the collaborative design of course } \\
\text { enhances the products but the actors and the organization too. } \\
\text {-A specific environment (more or less equipped regarding the needs } \\
\text { and the resources) is developed. }\end{array}$ \\
\hline
\end{tabular}

Note that two methods are not contradictory but complementary. Our purpose is to show in what case we have to select one of these and perhaps the both together for certain issues, as we will show for urban issues.

\section{Urban issue and design technologies 3.1. Context of transfer}

We have tried to find created and tested technological solutions to take complex systems into account. The relevant questions are: Finally, from the point of view of urban engineering, what best practices can potentially be adapted to town planning? If this is possible, how can industrial design solutions be adapted to urban issues?

If we agree that complexity is a common denominator between firms and cities, it should be noted that urban systems have a higher level of complexity than industrial systems. The main reason for this is the higher number of parts and potential but innumerable couplings in urban systems. 
In practice, in a metropolitan area, urban projects can have different sizes. They can focus on a builtup area, a town, a neighbourhood or a building in the urban environment, as shown in Figure 5 below based on research by Ingallina (2008). Over larger areas, more elements must be considered, and complexity consequently increases. Actually, scales or levels are paramount in the management of urban systems. Here, we only focus on urban issues within French metropolitan areas. Although certain approaches can be generic, every country has developed specific planning laws and town planning practices.

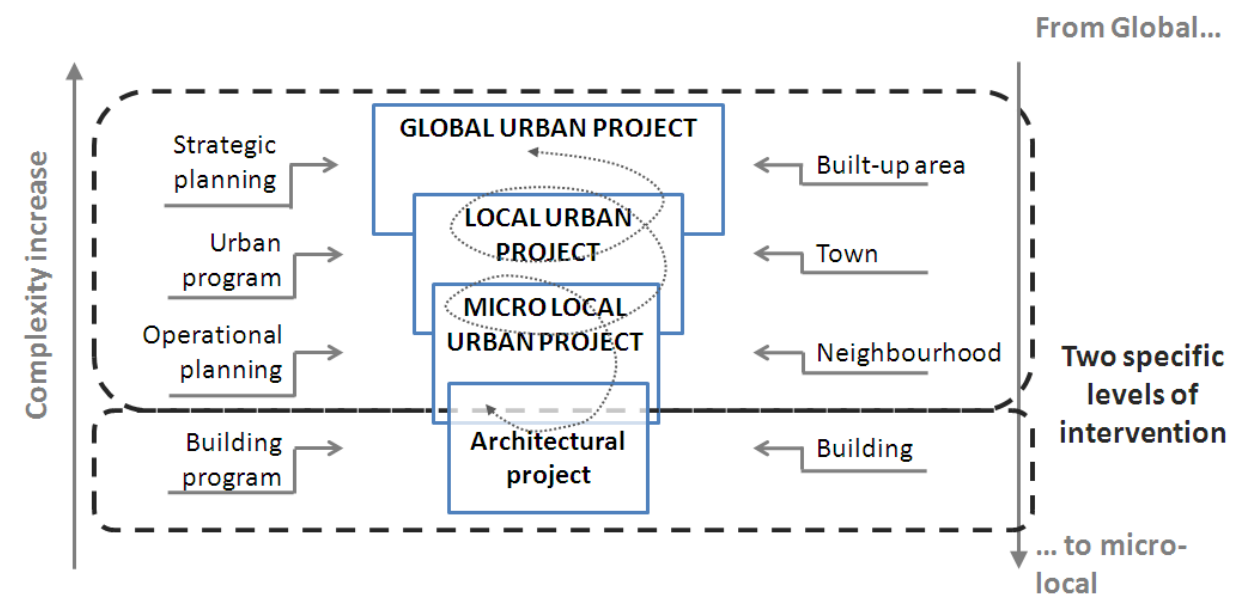

Figure 5: Two levels of intervention based on the scale of urban projects (adapted from Ingallina, 2008)

The differentiation of urban projects comprises two main components - the first (which ranges from global to micro-economic local urban projects) in which institutional actors are inevitably one of the main stakeholders (and often the contracting authority) and the second (architectural projects) where all of the main actors are private stakeholders.

\subsection{Focus of our research: Better consideration for the initial phase of urban issues}

Midler (1993) showed that a project's degree of freedom reaches a peak at the beginning of the development process, and that this freedom decreases as project knowledge levels increase. Freedom of choice during the initial stages is one of the pre-conditions for the inventiveness of a project. In addition, it is worth reiterating that the impact of design decisions is initially very high, and then declines steeply as the design matures (Wang, 2002). It is therefore vital to provide the best information and decisions as early as possible in order to maximise the use of this freedom. This occurs in industrial circles, when all of the "designers" work together at a much earlier stage. Studies should be focused on the early design stage in order to develop efficient opportunities. In urban development, to improve the availability of information as well as to allow objectives to be complemented, and visions established at an earlier stage, stakeholders should share knowledge and idea. The aim of this research is to facilitate the selection of several possible scenarios through increased and enhanced knowledge levels during the initial stages of urban projects. Furthermore, the early stage of urban design refers to conceptual design - the goal is therefore to assist in the emergence and definition of concepts which will allow the improved formulation of the meaning, planning and programs for a project.

Since the beginning of the 2000's, some European urban research studies have in fact focused on the initial stage of urban projects (Allen, Bonetti and Laforgue, 2008; Arab, 2004; Mahmoud-Jouini, 2003; Gerber, 2003; Prost, 2003; Janvier, 2001; Nykanen, 2007). Nykanen (2007) has studied a procedure called collaborative urban planning that "enables concurrent interactive cooperation between city planning units and companies in preparing city plans and developing companies' project plans" at the initial stage of planning in Finland. We can also refer to the Neighborhood Planning of 
Seattle described by Sirianni (2007) as collaborative democratic design.

Thus, a review of urban studies, supported by our experience in planning agency, indicates the increasingly important role of the early stages of urban projects. This phase is viewed as the stage for the collective elaboration of initiatives to tackle urban issues (Janvier, 2001; Arab, 2004). Prost (2003) however explains that the early phase of urban projects sometimes constitutes a "chaotic debate platform".

The French community seems agreed on the importance of also viewing the initial stage as a phase of design (Mahmoud-Jouini, 2003; Prost, 2003). But whereas certain concepts and tools derived from management or engineering (concurrent engineering in particular) are used to deal with urban issues (Arab, 2004; Avitabile, 2005), a lack of methodology originating from the design sector can be observed, except in the architectural and building sectors which we reviewed (Kvan 2000, Rosenman et al., 2007). It is clear that other technological solutions may help professionals to work together and to provide a new, more efficient approach to urban issues. The adaption of industrial technologies from the design sector should provide certain time savings in the development of methodologies dedicated to urban development.

Further analysis is now required in order to determine the need for urban engineering to develop tools, methodologies and environments to better consider the initial phase in urban issues.

\section{Distributed collaborative design as an adapted methodology for urban issues}

\subsection{Which strategy should we transfer to an urban design process?}

When a group of actors tackles an urban issue, we can compare this eclectic group to a design actors' team whose objective would be to generate a design (urban) project. It consists in expressing one or several solutions to tackle the identified issue. In addition, a mass of actors can get involved during the design of the project in a contingent way. Moreover a company will be able to federate around vital objectives as its need of durability. What will a priori incite it to be more profitable and consequently design products which will be successful on the market. Furthermore an urban system cannot be reduced to a group of actors that can be mobilized around a smaller common denominator such as the pursuit of "survival" in the economic world. It is a bit of a caricature view but it is at least an essential differentiation between companies and territories (even if territories are seen as competitors from one another). Even if all actors from a territory are not gathered by an only common objective, they still can be considered as design actors, thanks to their interactions with an ongoing conceptualization (and thereafter construction) project, according to what was presented before.

In this instance, we can identify a certain number of potential difficulties as the size of the team or the number of teams involved in a project; the more or less random selection of the different concerned actors contingent on the project context and environment; the political strategies and the general political frame of the realization. Furthermore, it is accepted in a company that collective work is not the panacea for all the multifaces processes. "In certain conditions, individually conducted activities may be more appropriate" (Visser, 2006, p.6). For all these reasons (no exhaustive) we can admit that neither the distributed design, nor the collaborative design, both considered individually, are not sufficient to take on challenges of an urban design improved in its practices and able to better understand the complexity of its environment. We need a more complete method to improve the design process of urban projects. It does not consist in choosing between the two design strategies but we must contemplate a third technological solution as contribution to an urban engineering. In other words, it does not consist in using either the first or the second strategy but to work together with all these strategies.

Finally, Distributed Collaborative Design (DCD) technology appears to be the most appropriate even if two different situations must be considered: A first level, where the stakeholders ${ }^{6}$ work

${ }^{6}$ Here, one stakeholder can be a community of practices. 
together/collectively or individually/alone in accordance with the moment (or stage) of the project in which they are involved; A second level, superior, where the actors work at the same time together and individually (see Table 2).

Table 2: Possible state of the design process all along an urban project (Our research)

\begin{tabular}{l|c|c|c}
$\begin{array}{l}\text { Different moments of } \\
\text { the project }\end{array}$ & $\begin{array}{c}\text { Definition and tasks } \\
\text { distribution }\end{array}$ & $\begin{array}{c}\text { Execution of the tasks thanks } \\
\text { to objectives (sub-project) : } \\
\text { task 1, task 2, ..., task n }\end{array}$ & $\begin{array}{c}\text { Interdependent and } \\
\text { gathered tasks }\end{array}$ \\
\hline $\begin{array}{l}\text { Level of the work } \\
\text { individual or collective }\end{array}$ & $\begin{array}{c}\text { Collaborative design } \\
\text { process }\end{array}$ & Distributed design process & $\begin{array}{c}\text { Collaborative design } \\
\text { process }\end{array}$ \\
\hline $\begin{array}{l}\text { Level of the work } \\
\text { individual and collective }\end{array}$ & \multicolumn{3}{c}{ Distributed collaborative design process }
\end{tabular}

\subsection{DCD and different kinds of urban issues}

To a certain extent, DCD is already practically applied in the understanding of urban issues. The technology has been applied for several years in the field of architecture, and has been described by a number of authors. Gabriel and Maher (2002) explain this evolution because in design, it is more important to 'see' what is being discussed rather than 'watch' the other people involved in the discussion. This position strengthens the role of the artefact as the central element in this process. Technology now enables virtual environments that allow real-time multi-users collaboration by designers in different physical locations (Roseman et al., 2007). Many research studies have contributed to this objective (Elsen and Leclercq, 2008; Slimani, Ghodous and Boujut, 2005; Wang et al., 2002). Design actors can therefore be distant (in spatial terms) but, thanks to Information Technology solutions, still have the physical possibility of working closely together.

As mentioned above, problems encountered in the (urban) design sector are large and complex, and many actors are mobilized in such instances. Due to the number of linked parts and actors, and considering urban development as an organisation with 'dialogic' purposes (i.e. conflicting, rival and complementary at the same time), it would be simplistic to consider only the computerised aspect of DCD in urban environments. Furthermore, this only addresses the technical aspect of the issue. Globally, DCD must propose tools, methods and environments dedicated to the initial stage of urban development design. The main objectives must however be to help stakeholders work together better and allow them to make decisions faster for the public interest.

In this context, DCD can offer distributed interfaces where communities of interest (Fischer, 2004) can work together. The DCD concept should allow the acquisition of more useful knowledge.

Here, it is proposed to provide two theoretical contributions for each level of intervention mentioned above - for architectural and urban projects.

\subsubsection{The pattern modelling method: Supporting DCD strategy}

Based on other researches (De Terssac and Friedberg, 2002; Jeantet, 2002), we suppose that the design process is a progressive objectification with the intervention of different actors to modify intermediate objectives with their points of view. In DCD context, we name these intermediate objectives "pattern". The patterns are the micro-objectives or micro-tasks of the design process. In fact, any pattern is at the same time an objective and a part of a design scenario. It integrates the actors who must be consulted, and the strategy, to achieve final objective. Patterns are linked with each other and they built a pattern system. As design process is a dynamic process, all tasks or objectives could not be predefined and will appear or change during the design process. So, this system should not be closed and should be able to be modified or updated.

Different researchers in various fields previously has used "pattern" concept in a design process. Originally, the concept of "patterns" has already been used in architectural and urban planning in the 
"pattern language" approach defined by Christopher Alexander et al. (1977). Based on the Alexander's definition of "pattern", the concept has been more developed in computer sciences and in knowledge management (Table 3):

Table 3: Different existing concepts of "Pattern"

\begin{tabular}{l|c|c|c}
\multicolumn{1}{c|}{ Concept } & Field & Definition & Author \\
\hline 1 & $\begin{array}{c}\text { Town planning and } \\
\text { architectural design }\end{array}$ & $\begin{array}{c}\text { A number of fundamental and reusable } \\
\text { rules }\end{array}$ & Alexander et al. 1977 \\
\hline $\mathbf{2}$ & $\begin{array}{c}\text { Interface design and } \\
\text { software engineering }\end{array}$ & Best practices & Meszaros, 2010; \\
Conte et al. 2001
\end{tabular}

The concept of "pattern" that is suggested in this research is a mixed approach. We defined "Pattern" a reusable design objective chosen between "best practices" in the urban issues (according to concepts 1 and 2) and linked to its knowledge elements (according to concept 3). In addition, our "Pattern" should be able to propose one or more solutions to a problem which should be justified with some real life examples.

Based on the defined concept of "pattern" we suggested a "Pattern modelling method" in which patterns need to be shared through a "growing open database of design problems and solutions" as it is suggested in the Alexander's theory of pattern language (Steenson, 2009). The patterns, their relationships and impacts are implemented and demonstrated in a "Pattern Database". This is a database of architectural and urban "best practices" of design. The patterns database describes and compares several patterns of the affected data using graphical displays and relationship diagrams from different points of view (Figure 6): involved actors, design strategy, necessary activities to implement each pattern, special considerations (e.g. environmental qualities, social qualities, economic advantages, etc.), relationships with other patterns.

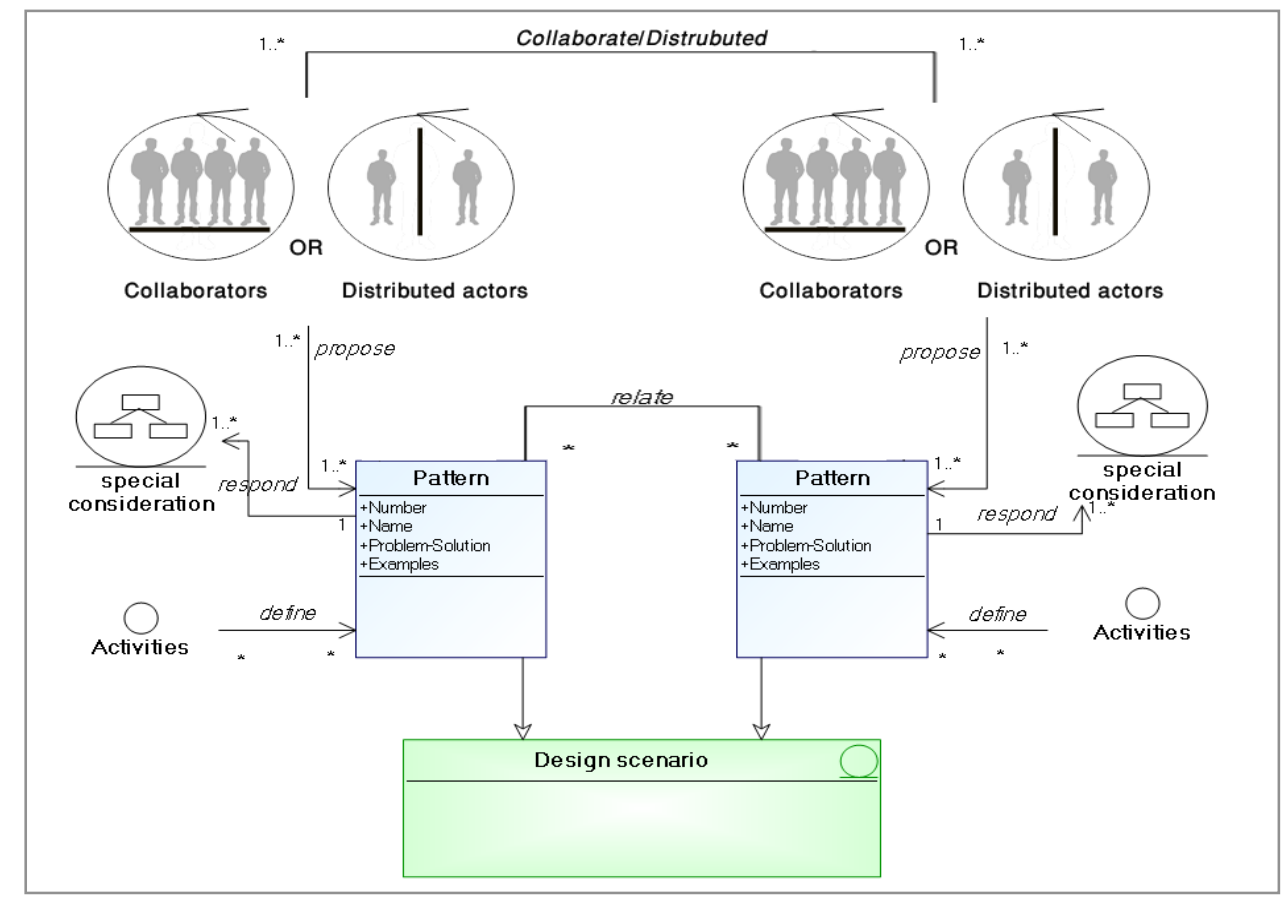

Figure 6: Pattern modelling method to support DCD strategy 
The pattern modelling method can provide for a design team to manage their design strategies according to the design tasks. However, any design task is not assumed to be an isolated object and is studied as part of a relational system. Analysing a pattern from different points of view reduces the risk of believing that the indexed solutions are viable in all situations.

The pattern modelling method allows the design team to better formulate its needs and to build its own "Design scenario" regarding its design context.

Design scenarios help design teams to estimate project collaboration requirements during the early stages of the design process.

Subsequently, the pattern approach can be applied on a digital database to simplify the consultation of this database as part of the remote collaboration process. The various actors in the design process are thus able to navigate and locate information that is useful to their projects. The possibility of defining several scenarios allows the design team to evaluate in real-time the impact of their choices in terms of project management. Finally, this database can be adapted to technical upgrades, data processing possibilities and specialised new considerations (such as environmental or end-user issues).

This method provides the design team with objective modelling rather than problem modelling. The main feature of this method is the capitalisation of knowledge, and the sharing and exchange of knowledge through its patterns.

\subsubsection{Proposal for a collaborative workspace}

It is possible to imagine a single specific workspace dedicated to urban development where various people and groups can work together at the same or at different times. In fact, collaborative workspaces already exist (Dupont, 2009) But these organisations are focused on innovation and new products and do not specifically refer to DCD technology. In practice, however, their aim is to allow different professionals to collaborate more effectively. We did not identify such usual structure dedicated to urban issues, we propose then putting the theoretical bases to develop one.

In terms of urban development, we suggest the creation of a generic framework for a collaborative workspace. The DCD process needs to consider two specific aspects: the material dimension and the human dimension. Each facet appears differently according to the level of interaction ${ }^{7}$ in the process (Table 4). In other word, they express different properties according to the level observed. It is thus possible to be concentrated on the separate elements (Tools and methods / Actors) as a first level. As a second level, we can focus on the interactions and the factors which allow these interactions (Interface / Team of design actors). Finally, we can then observe Parts and Links as a whole (Environment / Team of teams) at the third level.

Table 4: Material and human dimensions of the DCD process

\begin{tabular}{c|c|c|c}
\multirow{2}{*}{ Level } & DCD Process & Material dimension & Human dimension \\
\hline 1- Parts & Distributed & Tools and methods & (Various design) actors \\
\hline 2- Links & Collaborative & Interfaces & Team \\
\hline 3- Parts and links & $\begin{array}{c}\text { Distributed and Collaborative } \\
\text { (D-C) }\end{array}$ & $\begin{array}{c}\text { Environment } \\
\text { (real or virtual) }\end{array}$
\end{tabular}

All of these elements play a vital role. In addition, they are mutually interrelated. We can notice that the higher the level of interaction, the more the temporal and spatial distances decrease (virtually or

\footnotetext{
${ }^{7}$ The level of interaction should be understood in terms of the complexity theory. The first level is less complex than the second, which is in turn less complex than the third.
} 
otherwise), not only between the material elements and between human beings, but also between people and the material elements. This process can be illustrated by research authored by Caelen (2004b) on experiments with the Multicom platform. The author uses the concept of design "moments" which can be described as a set of tasks ${ }^{8}$. In fact, it is possible to view each "moment" as a period of interaction between tools/methods and actors. In addition, we can add that coordinator(s) / facilitator(s) / organiser(s) are required for each situation, particularly for the second and third level.

Furthermore, as shown above, if the process remains at the first level, it is possible to create a collective design but the final product will comprise the addition of several sub-products. Conversely, at the second and especially third levels, the final product is closely influenced by numerous factors along the entire process. Thus, at the end of the process, the results of the DCD process include shared artefacts/concepts and shared knowledge.

All of these elements constitute an "ecosystem" which can be modelled (Figure 7).

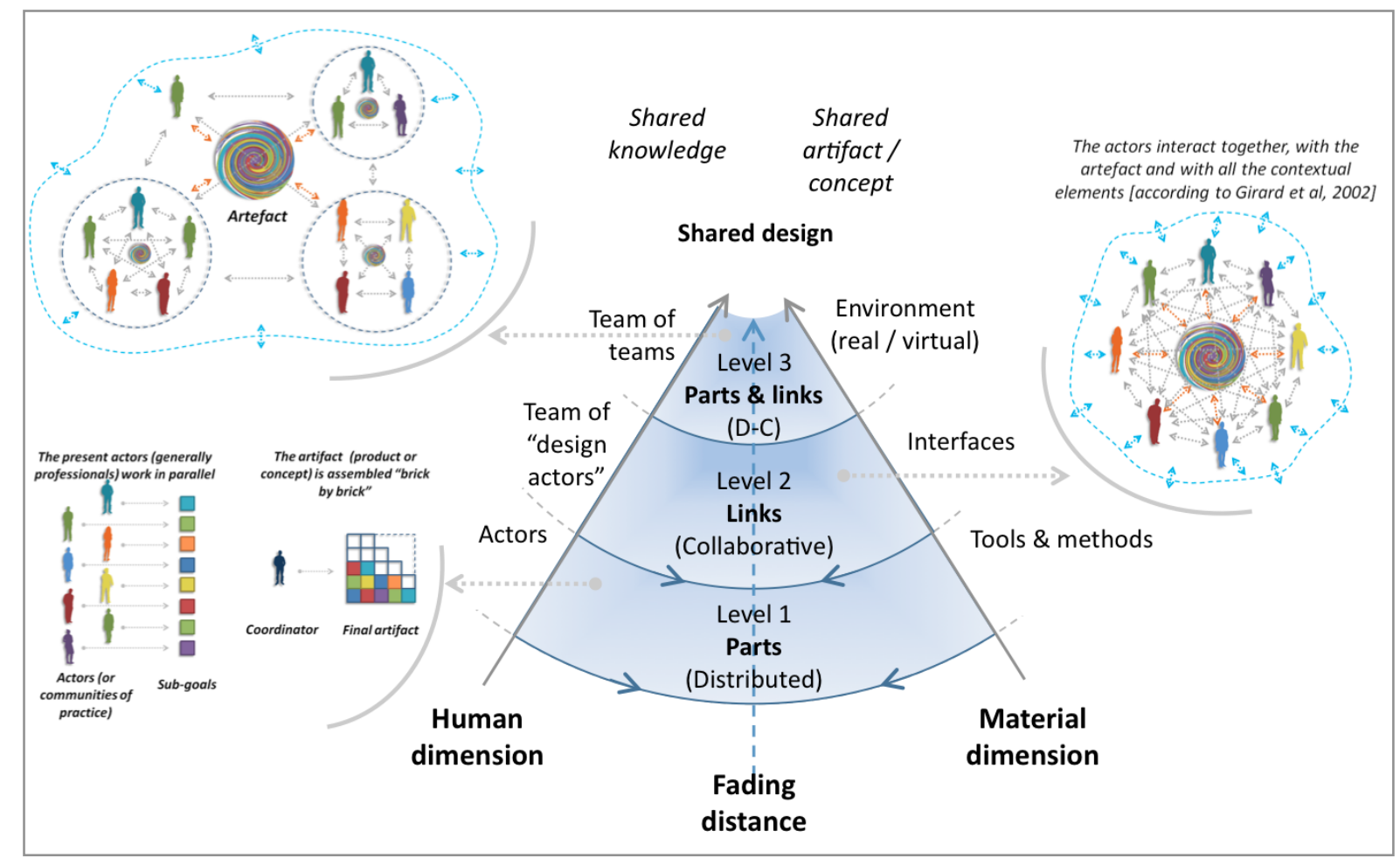

Figure 7: Model of ecosystem generated by DCD Process

When dealing with urban development, it appears to be more beneficial to have a dedicated reference space in a city to allow actors (especially decision-makers) to manage and coordinate the extended collaborative design process. The purpose of this model is to allow researchers or professionals to develop a collaborative workspace which attempts to take all fundamental dimensions into account. Among these dimensions, we can specify that many of the decisions made about urban systems are political. In other words, urban projects are developed toward a political framework. So, among actors of the design to be included in DCD process, there are the political decision-makers. It is therefore necessary to take into consideration powerful political influences on the systems.

\footnotetext{
${ }^{8}$ Caelen quotes the following examples: brainstorming, functional analysis, value analysis, design of scenarios, cognitive walkthroughs, prototyping, end-user testing
} 


\subsection{Debate: Role of the end-user in urban development?}

Another important question may be raised - the end-user is currently absent from the early stages of urban development projects; he is merely an "abstract agent", a talking point. A further dilemma is the way in which to select a user or end-user and involve them in the design process. Industrial circles already emphasise that it is sometimes hard to describe a single end-user for a specific product, e.g.: an aircraft (Darses, 2004).

As in corporate environments, the incorporation of end-users' perspectives as soon as possible into discussions on urban issues seems a particularly delicate one. The multiplicity of uses, their potential inconsistencies and the diversity of associated sets of end-users (such as citizens, institutional actors, politicians, associations and economic agents) generate conflicting, rival but possibly also complementary purposes.

Furthermore, according to the detailed literature reviews of Wang et al. (2002) the initial stage of design refers to conceptual design. The author shows that conceptual design issues are highly interdisciplinary, and often involve collaboration between customers, designers and engineers. However, customer requirements are on the one hand mapped to functional specifications and on the other hand a design team attempts to develop multiple alternative design solutions from functional specifications. Wang's study shows that customers are not directly included in this collaborative process. "Design" actors are separated. Thus, are customers to be considered designers? Considering the difficulties encountered in industrial applications, how can DCD help to develop a new status for end-users in urban development?

This point emphasises one particular limit to our theoretical approach to urban engineering. We will undoubtedly need to draw from other scientific fields. With regard to the issue of end-users, the field of innovation, with "open innovation" and "user-driven innovation" in particular, can provide interesting food for thought. This point also implies that specific initiatives in the political sciences and the debates over the roles attributed to the various actors (notably powerful political influences) in the urban environment must be considered. Other works can be also analyzed as the method developed by Salingaros (2005), using the work of Christopher Alexander et al. (1977), which allows inhabitants of a particular neighbourhood to participate in planning their own environment.

\section{Conclusion}

Our study has only scratched the surface of exploiting the possibilities of technological transfer from the design sector to urban engineering. Distributed collaborative design appears to be an interesting contribution to the definition of urban engineering concepts and may have a broad potential for development in order to better respond to customer needs. In addition, technological transfer research targeting social and environmental benefits means that decision-making and design teams not only gain access to each other's technological capabilities but also develop and share knowledge about organisational aspects. This can result in a more stable and shorter conceptualization process (concept design) and thus to increase economic benefits.

Obviously, experience has shown that this theoretical approach requires strengthening, because the methodology is being transferred from a sector which is less complex than an urban system. The debate over the use or the end-user is one specific example of the numerous potential questions which may arise. Globally, we know that the various locations of the specific actors have a very powerful effect on project processes. This dimension is particularly acute in urban development. With this in mind, it appears not only necessary to use other technologies rooted in industrial applications (we have so far only evoked those evolved from questions of innovation), but it is also advisable to draw a parallel with the variety of methods of public participation described in political science. Another issue is given by the notion of artefact which underlines that it is necessary that the team has and controls suitable tools of representations adapted in order to visualize, create a model and understand 
the concepts worked in common. The question of equipment particularly shouts at in the scope of complex projects such as the urban projects. Do we have to, can we, and if necessary, how must we represent a complex study object in all its dimensions (as qualitative as quantitative)?

Indeed, for the moment, our theoretical models can be considered sources for further connections. However, connection (which sometimes only involves communication) and collaboration are not synonyms. A shift in practice and knowledge must take place in order to give urban engineering a global purpose. Indeed, our works underline the great importance of the management of knowledge and intellectual properties (definition and production of different "knowledges", plus their negotiation, combination, integration throughout the collaborative processes). This subject needs the development of a specific research base about urban systems. That shall be the object of further multidisciplinary works.

To sum up, here we proposed a theoretical approach suggesting that a Distributed Collaborative Ecosystem can be generated by a specific collaborative workspace. We highlight the potential contribution of the conceptualisation of the urban projects to enrich the vision of the decision-makers. We also underline the borders of our approach, the necessity to bring answers to new questions and to use other knowledge and know-how. Indeed, in case of urban issue, our experience shows us it is relevant to choose an ad hoc approach then to formulate (when it is possible) a generic concept. So, it becomes necessary to use a research action methodology (Checkland and Holwell, 2007). This framework will contribute to demonstrate that a distributed collaborative process can increase the efficiency and the quality of (the management of) urban projects. We can briefly sketch the protocol of research which could be implemented during our works, namely:

1) Explorative stage: the researcher confronts a real world problem situation using the framework and the methodology mentioned above in order to:

- Establish the different issues linked to the distributed collaborative processes in the urban systems and for the urban projects,

- Identify the area of interest (cases to be observed, as an urban area) where the researcher shall be involved,

- List and describe tools and processes developed by the actors concerned by the field,

- Analyse if these elements are in a distributed, collaborative, or distributed collaborative processed.

2) Action stage: the researcher takes part in the real world and acts in situation in order to:

- Conceptualise and develop systems/processes based on distributed collaborative approach,

- Test these systems/processes in the studied ecosystem and collect qualitative and quantitative information.

3) Reflection stage:

- Compare the observed cases and the developed systems,

- Establish the key factors which are necessary to promote the development of a Distributed Collaborative Ecosystem in the real word,

- Identify the tools and methods (i.e. the technologies) that can support - and accelerate - the spread of distributed collaborative approach in urban system, i.e. presence of the key factors.

4) Enrichment of the state of art:

- Publish regularly our results to confront them to the scientific community,

- Reproduce / Adjust the process of research if it is necessary,

- Develop new scientific issues.

Note that the action research is an iterative process, so the phases are often in evolution.

Acknowledgments: The research described benefited from the support of ADUAN and CNFPT. 
Draft - Dupont et al 2012 From urban concept to urban engineering: ...

See published version : http://dx.doi.org/10.1080/13574809.2012.666208

\section{References}

Alexander, Ch. Ishikawa, S. and Silverstein, M. 1977. A Pattern Language. New York: Oxford University Press.

Allen, B. Bonetti, M. and Laforgue, J.D. 2008. La contribution de la recherche à la conception de projets urbains. Annales de la recherche urbaine, 104, pp. 110-119.

Amin, A. and Cohendet, P. 2004. Architectures of Knowledge: Firms, Capabilities, and Communities. Oxford: Oxford University Press.

Arab, N. 2004. 'L'activité de projet dans l'aménagement urbain: Processus d'élaboration et modes de pilotage ; Le cas de la ligne B du tramway strasbourgeois et d'Odysseum à Montpellier'. Thesis (Ph.D.), Ecole Nationale des Ponts et Chaussées, Paris.

Belkadi, F. Bonjour, E. and Dulmet, M. 2004. 'Démarche de modélisation d'une situation de conception collaborative'. Coopération et organisation numérique, 8 (1), pp. 93-106, viewed 30 Octobre 2010, $<$ http://hal.archives-ouvertes.fr/docs/00/29/46/86/PDF/Hal-Belkadi_2004-conception_collaborative.pdf $>$.

Brassac, C. Grégori, N. 2003. 'Éléments pour une clinique de la conception collaborative', Actes du dixième atelier: Le Travail Humain: Modéliser les activités coopératives de conception, Paris, pp. 73-92.

Buzan, T. B. 2000. Mind Mapping. Paris : édition d'Organisation.

Caelen, J. 2004a. Le consommateur au cour de l'innovation. Paris : CNRS Sociologie.

Caelen, J. 2004b. 'Conception participative des objets interactifs : principes, méthodes et instrumentation', Presented to Ecole d'été TIC et société. Carry le Rouet.

Checkland, P. and Holwell, S. 2007. 'Action Research - Its Nature and Validity', In: Kock, N. eds. Information Systems Action Research: An Applied View of Emerging Concepts and Methods, Laredo, Texas: Springer Science, pp. 3-17

Chen, Y.J. Chen, Y.M. and Chu, H.C. 2008. Enabling collaborative product design through distributed engineering knowledge management. Computers in Industry, 59, pp. 395-409.

Conte, A. Fredj M. Giraudin, J.P. Rieu, D. 2001. P-Sigma : un formalisme pour une représentation unifiée de patrons. Genève: Inforsid.

Darses, F. Falzon, P. 1994. 'La conception collective : une approche de l'ergonomie cognitive', In: G. De Terssac and E. Friedberg, eds. Coopération et Conception, Toulouse : Octarès.

Darses, F. Détienne, F. Falzon, P. and Visser, W. 2001. A method for Analysing Collective Design Processes. Rapport de Recherche INRIA, viewed 30 Octobre 2010, <http://hal.inria.fr/inria-00072330/>.

De Terssac, G. 1996. 'Le travail de conception : De quoi parle-t-on ?', In: G. De Terssac and E. Friedberg, eds. Coopération et Conception, Toulouse : Octarès.

Dieng-Kuntz, R. C. 2001. Méthodes et outils pour la gestion de connaissances, Paris : Dunod.

Dupont, L., 2009. 'Transfert du génie industriel vers l'ingénierie urbaine : vers une approche collaborative des projets urbains'. Thesis (Ph.D.), Institut National Polytechnique de Lorraine, Nancy.

Elsen, C. and Leclercq, P. 2008. "SketSha": The sketch power to support collaborative design. Computer Science, 5220/2008, pp. 20-27.

Fischer, G. 2004. 'Social Creativity: Turning Barriers into Opportunities for Collaborative Design'. Proceedings of the Eight Participatory Design Conference: Artful Integration: Interweaving Media, Materials and Practices, July 27-31, Toronto, pp. 152-161.

Gabriel, G.C. and Maher, M.L. 2002. 'Coding and modelling communication in architectural collaborative design'. Automation in Construction, 11, pp. 199-211.

Gerber, C. 2003. 'Etude exploratoire de l'offre d'expertise relative à la phase amont des opérations de construction et d'aménagement', In : R. Prost, eds. Projets architecturaux et urbains. Mutations des savoirs dans la phase amont, Paris : PUCA.

Girard, P. Merlo, C. and Doumeingts, G. 2002. 'Approche de la performance en conduite de l'ingénierie de la conception'. Paper presented to 4th International Conference on Integrated Design and Manufacturing in Mechanical Engineering (IDMME 2002), Clermont-Ferrand, May 14-16.

Grebici, K. 2007. 'La Maturité de l'Information et le Processus de Conception Collaborative'. Thesis (Ph.D.), Institut National Polytechnique de Grenoble, Grenoble.

Grégori, N. and Brassac, Ch. 2001. 'La conception collaborative d'artefacts'. Acte en ligne d'Epique 2001 : Activités cognitives en situation dialogique, pp. 21-31 viewed 30 octobre 2010, <http://www.univnancy2.fr/pers/brassac/PublicationsBrassac.pdf/epique.pdf $>$.

Hou, J. Su, C. and Wang, W. 2008a. 'Knowledge management in collaborative design', Proceedings of the International Conference on Service Operations, Logistics and Informatics, 1, pp. 848-852.

Hou, J. Su, Ch. Zhu, L. and Wang, W. 2008b. 'Partner selection system for collaborative design', Proceedings of the International Symposium on Computational Intelligence and Design, 2, pp. 317-321.

Hou, J. Su, C. Su, Y. and Wang, W. 2008c. 'Integration of knowledge management and collaborative design', Proceedings of the International Conference on Intelligent Computation Technology and Automation, 2, pp. 
Draft - Dupont et al 2012 From urban concept to urban engineering: ...

See published version : http://dx.doi.org/10.1080/13574809.2012.666208

743-747.

Ingallina, P. 2008. 'Le projet urbain. Que sais-je ?'. 3rd ed. Paris : PUF.

Janvier, Y. 2001. 'Un système de production en mutation', In: A. Masboungi eds. Fabriquer la ville; Outils et méthodes : les aménageurs proposent, Paris : La Documentation française.

Jeantet, A. T. 2002. 'La coordination par les objets dans les équipes intégrées de conception'. In: G. De Terssac and E. Friedberg, eds. Coopération et conception. Toulouse : Octarès, pp. 87-100.

Klein, M. Sayama, H. Faratin, P. and Bar-Yam, Y. 2003. 'The Dynamics of Collaborative Design': Insights from Complex Systems and Negotiation Research Concurrent Engineering September , 11, pp. 201-209.

Kvan, T. 2000. 'Collaborative design: what is it?'. Automation in Construction, 9, pp. 409-415.

Le Moigne, J.L. 1993. La modélisation des systèmes complexes. Paris : Dunod.

Lu, S.C.Y. Cai, J. Burkett, W. and Udwadia, F. 2000. 'A Methodology for Collaborative Design Process and Conflict Analysis'. Annals of the ClRP, 49(1), pp. 69-73.

Mahmoud-Jouini, S.B. 2003. Pratiques de projet et ingénieries, Tome III: Co-conception et savoirs d'interaction, Collection Recherche 145. Paris : PUCA.

Meszaros, G. s.d. 'A Pattern Language for Pattern Writing'. The Hillside Group. viewed 20 Mai 2010, $<$ http://hillside.net/language-for-pattern-writing $>$

Midler, C. 1993. L'auto qui n'existait pas : Management des projets et transformation de l'entreprise. Paris : InterEditions.

Monod, J. 1970. Le hasard et la nécessité : Essai sur la philosophie naturelle de la biologie moderne. Paris: Seuil.

Morin, E. 2005a. 'Restricted Complexity, General Complexity'. Presnented to Colloquium Intelligence de la complexité : épistémologie et pragmatique, June 26, Cerisy-La-Salle. Translated from French by C. Gershenson. Morin, E. 2005b. Introduction à la pensée complexe. Paris: Seuil.

Nykanen, V. 2007. 'Collaborative urban planning: Case beyond Vuores VTT Tiedotteita'. Valtion Teknillinen Tutkimuskeskus, 2393, pp. 1-97.

Prigogine, I. 1996. 'Irréversibilité et instabilité des systèmes complexes'. In: S. Hawking. et al., eds. La mort de Newton. Paris : Maisonneuve et Larose, Collection Prometheus, pp. 107-132.

Ribière, M. 1999. 'Représentation et gestion de multiples points de vue dans le formalisme des graphes conceptuels'. Thesis (Ph.D.), Université de Sophia Antipolis, Nice.

Robin, V. Rose, B. and Girard, P. 2007. 'Modelling collaborative knowledge to support engineering design project manager'. Computers in Industry, 58, pp.188-198.

Rosenman, M.A. Smith, G. Maher, M.L. Ding, L. and Marchant, D. 2007. 'Multidisciplinary collaborative design in virtual environments'. Automation in Construction, 16, pp. 37-44.

Salet, W. 2008. 'Rethinking Urban Projects: Experiences in Europe'. Urban Studies, 45(11), pp. 2343-2363.

Salingaros, N.A. 2005. Principles of urban structure. Amsterdam: Techne Press.

Shen, W. Norrie, D.H. and Barthes, J.P. 2000. Multi-Agent Systems for Concurrent Intelligent Design and Manufacturing. London: UK Taylor and Francis.

Sirianni, C. 2007. 'Neighborhood Planning as Collaborative Democratic Design'. Journal of the American Planning Association, 73(4), September, pp. 373-387.

Slimani, K. Ghodous, P. and Boujut, J.F. 2005. 'Knowledge Management System for Cognitive Synchronization in Collaborative Design', In: International Conference on Concurrent Enterprising, June 2022, University BW, Munich.

Steenson, M.W. 2009. 'Problems before patterns: A different look at Christopher Alexander and pattern languages'. Interactions, 16(2), pp. 20-23.

Visser, W. 2006. The cognitive Artifacts of designing. London: Lawrence Erlbaum.

Visser, W. Darses, F. and Détienne, F. 2004. 'Approches théoriques des activités de conception en psychologie ergonomique', In: J.M. Hoc and F. Darses eds. Psychologie Ergonomique : tendances actuelles. Paris : PUF, pp. 97-118.

Wang, L. Shen, W. Xie, H. Neelamkavil, J. and Pardasani, A. 2002. 'Collaborative conceptual design-state of the art and future trends'. Computer-Aided Design, 34(13), pp. 981-996.

Wang, W. Hou, J. Su, C. Liang, S. and Su, Y. 2008. 'Modeling on conflict resolution of collaborative design', In: Proceeding of the International Conference on Wireless Communications, Networking and Mobile Computing, pp.1-4. 